\title{
Comunicación

\section{La comunicación presidencial en México 1988-2012: cuatro lecturas de un libro necesario}

FRIDA V. RODELO ${ }^{1}$

El libro La Comunicación Presidencial en México 1988-2012 se permite ser varios libros a la vez. Me explico: es, primero, un relato que a partir de cuatro entrevistas nos permite entender desde un punto de vista poco común la relación prensa/poder en México. Sobre esta, los académicos se han valido más del testimonio de los periodistas y gente de medios, lo que puede propiciar que en las escuelas de Comunicación y Periodismo tendamos a juzgar las situaciones desde este punto de vista y a prejuzgar negativamente a los actores gubernamentales. Este tipo de testimonios ayuda a conocer mejor lo que hacen dichas dependencias, así como a balancear nuestra forma de pensar en las oficinas de Comunicación. Asimismo, las fallas de los periodistas mencionadas dentro de los testi-

1 Universidad de Guadalajara, México.

Correo electrónico: viri.rodelo@gmail.com 
monios enriquecen nuestra mirada acerca de la relación entre los medios y los gobiernos. En ambos casos hablamos de actores que persiguen por distintas razones el objetivo de posicionar maneras de interpretar la realidad. ${ }^{2}$ En palabras de los autores, los estrategas de comunicación política desean "conseguir un lugar en la agenda mediática para los mensajes que el gobierno quiere transmitir a la sociedad" (p. 24).

La parte testimonial de la obra ocupa las presidencias de Salinas (1988-1994), Zedillo, (1994-2000), Fox (2000-2006) y Calderón (20062012). Así, un poco recordando a La Herencia (Castañeda, 1999), los autores de esta monografía recurren a los testimonios de los titulares de la oficina de Comunicación de Presidencia a lo largo de cuatro sexenios, con lo cual nos enteramos sobre el manejo de la comunicación gubernamental desde dentro de la Presidencia de la República en sus respectivos contextos. José Carreño Carlón, por ejemplo, comenta su consternación ante la ausencia de manuales de manejo de crisis en las instituciones gubernamentales mexicanas cuando se dio el levantamiento zapatista en Chiapas, mientras que Marco Provencio Muñoz explica crudamente en qué consistían los convenios de la Presidencia con los periódicos y lo que implicó la derrota electoral del Partido Revolucionario Institucional (PRI) en 2000 para el equipo de comunicación de Zedillo.

El análisis de Meyenberg y Aguilar abarca en realidad un mayor abanico temporal, lo cual me lleva a comentar mi segunda manera de leer este libro: como un marco teórico y contextual de la comunicación presidencial en México. En los primeros capítulos se abordan los antecedentes de la comunicación presidencial en México durante el siglo XX. Siguiendo las pistas de los pocos trabajos sobre el tema en México -uno de estos, el de Hernández Lomelí (1995), publicado en esta misma revista-, los autores explican cuáles han sido los cambios en el manejo de la comunicación del presidente, así como las razones de estos. La primera etapa de comunicación presidencial (desde la Revolución hasta

2 Si bien, los periodistas y organizaciones de medios pueden sustentar las actividades con las que brindan interpretaciones sobre el acontecer bajo muy diversos $-\mathrm{o}$ incluso contradictorios- fundamentos ideológicos, como muestran las mediciones de valores profesionales en el periodismo (Márquez, 2012). 
aproximadamente la década de 1950) es descrita por los autores como una etapa de propaganda en la que "la persuasión se ejercía a través de las estructuras de partido hegemónico más que a través de las oficinas operativas de la Presidencia" (p. 9). La segunda etapa es descrita como "más institucionalizada", pues "comenzaron a adoptarse las técnicas y las estrategias del modelo estadounidense, con el fin de difundir mensajes destinados a destacar los resultados de la gestión del gobierno y a explicar la lógica de las políticas públicas" (p. 9).

De acuerdo con Meyenberg y Aguilar, los procesos de democratización y liberalización, junto con las tecnologías, han influenciado cambios en el modelo de comunicación presidencial para que exista un mayor balance entre los tres principales actores involucrados (políticos, periodistas, opinión pública) en una relación que deje de tener como consigna el intentar "manipular" la opinión pública (para lo cual se buscaba "controlar" a los medios), para adoptar como objetivo el intentar "convencer" y "persuadir". En la primera entrevista, José Carreño Carlón, coordinador de Comunicación Social durante el periodo presidencial de Carlos Salinas, afirma que "era un tiempo ... en el que los medios y sus operadores necesitaban más del sistema político que éste de ellos. Hoy el sistema político necesita más de los medios” (p. 109).

Los autores también introducen en el libro la idea de que son las presidencias de Salinas (con José Carreño Carlón) y Fox (con Rubén Aguilar, coautor del libro) las que proponen en México, ante la apertura democrática, una manera diferente de manejar la comunicación del presidente de la República, con principios tales como conocer lo que opina la gente -principalmente a través de encuestas de opinión pública-, buscar persuadir (en vez de solo informar) sobre la bondad de las acciones de gobierno, y hacer storytelling (es decir, narrar historias) para acercar la figura del presidente a la gente. Como una especie de epílogo, se realiza una breve evaluación del manejo comunicacional del actual presidente Enrique Peña Nieto. Si bien no se suministra alguna entrevista al encargado del área durante este periodo, se vierte un breve análisis de la estrategia de comunicación de este gobernante, así como juicios sobre esta (adelanto: desfavorables).

Una tercera lectura del libro nos entera acerca de cómo funciona en la práctica actual la Coordinación de Comunicación Social de la Pre- 
sidencia de la República, pues los autores nos describen en el décimo capítulo su estructura organizacional, método y división del trabajo, así como sus productos informativos. La rutina de trabajo "24/7" de esta oficina implica monitoreos, síntesis de medios y transcripciones, pero también análisis, relación con medios -incluyendo prensa de todos los sectores en el nivel local, nacional e internacional-, logística, entre otras actividades. Este capítulo es complementado por los testimonios de los directores de Comunicación Social.

Creo que una cuarta manera de leer este libro es como un seguimiento, ahora desde la comunicación, a la crítica contra el gobierno de Felipe Calderón vertida en Los Saldos del Narco: El Fracaso de una Guerra (Aguilar \& Castañeda, 2012), así como en otras obras y apariciones públicas. Viene al caso comentar que mi anterior afirmación de que estos testimonios vienen "desde dentro" resulta literal, pues la dupla de escritores de este libro formó parte de uno de los cuatro equipos de comunicación analizados y Aguilar continúa brindando servicio profesional a numerosos gobiernos. Una lectura crítica no puede soslayar este hecho que, sin embargo, no basta para desacreditar la presente obra: desde mi punto de vista, estas cuatro formas de leer el libro aportan y llenan un hueco en un área disciplinar -la comunicación gubernamental- sobre la que se ha escrito muy poco en México.

\section{Referencias bibliográficas}

Aguilar, V. R. \& Castañeda, J. G. (2012). Los saldos del narco: el fracaso de una guerra. Ciudad de México: Punto de Lectura.

Castañeda, J. G. (1999). La herencia. Arqueología de la sucesión presidencial en México. Ciudad de México: Alfaguara.

Hernández Lomelí, F. (1995). Las oficinas de comunicación social en México. Comunicación y Sociedad, 25-26, 57-72.

Márquez, M. (2012). Valores normativos y prácticas de reporteo en tensión: percepciones profesionales de periodistas en México. Cuadernos de Información, 30, 97-110. 